\title{
RSEI. Revista de la Sociedad Española de Italianistas
}

\author{
Vicente González Martín` \\ Universidad de Salamanca
}

Hablar de una Revista en la que estoy involucrado muy directamente, pues soy su Director desde su creación en el año 2000 hasta la actualidad, es una tarea bastante complicada, pues la objetividad puede resentirse muy fácilmente. Por esa razón procuraré ser lo más descriptivo posible en el análisis, dejando los juicios valorativos a quien desee hacerlo.

El propio título: RSEI. Revista de la Sociedad española de Italianistas, define de alguna manera su idiosincrasia pues revela de forma explícita que es el medio fundamental de la difusión de los resultados científicos de los italianistas espanooles, agrupados en torno a una sociedad científica, aunque siempre abierto a las aportaciones de los de otros países.

La Asociación Española de Italianistas, creada en 1974 y transformada en Sociedad Española de Italianistas algunos años después, pasando de ser una asociación gremial a una sociedad de estudios, sintió desde los comienzos la necesidad de plasmar en papel y difundir sus investigaciones a través de publicaciones en las que se recogieran los resultados investigadores de sus miembros. Por esa razón, desde 1980 comenzaron a celebrarse congresos bianuales de los que emanaron diversos volúmenes de actas publicadas en su mayor parte en las editoriales de diferentes universidades españolas.

Sin lugar a dudas, el acervo de italianismo que los volúmenes publicados atesoran es de gran consistencia y continúan siendo un referente para los italianistas españoles y de todo el mundo. Sin embargo los tiempos fueron cambiando y la SEI, abriéndose a italianistas de diferentes países, adquirió una consistencia humana y científica cada vez más amplia y especializada en el mundo científico. A remolque de las tendencias que provenían de las ciencias experimentales y del mundo anglosajón se fueron imponiendo las revistas como cauces más adecuados para la difusión de los resultados de la investigación en todas las áreas del conocimiento.

Atendiendo a esas tendencias, la Sociedad Española de Italianistas decidió crear su propia revista, la que surgió con un triple deseo: 1) ser una tribuna abierta a la colaboración de los italianistas españoles y de otros países; 2) exigir a ultranza 
la seriedad y el rigor científicos de los investigaciones que acogiera y 3) mantener su continuidad pese a las dificultades que, sin lugar a dudas, se presentarían. Al tiempo de sostener señas de identidad que la caracterizarían por ser el órgano de una sociedad científica, por el rigor en la selección de los textos, el multilingüismo, aunque, como es obvio, primando el italiano y el español, y la apertura de temáticas — siempre dentro de la línea del italianismo.

Por razones estratégicas de hacer coincidir tanto al Presidente en aquellos momentos de la SEI y al Director de la Revista, el profesor Vicente González Martín, y en razón de facilidades editoriales, se decidió establecer la sede en la Universidad de Salamanca y encargar a Ediciones de la Universidad de Salamanca su publicación, siendo el Área de Filología Italiana de esta Universidad la que ha financiado todos los números hasta ahora publicados.

Con estas premisas, en el año 2000 se publicó el número 0 de RSEI con un contenido muy especial, pues era la primera prueba de una aventura editorial que no queríamos que siguiera el repetido aforismo español de que «las revistas duran lo que las pajas en las eras». Para conjurar esa amenaza se decidió hacer un número especial en el que los diversos colaboradores — nueve concretamente- fuesen reconocidos escritores italianos y sus textos fueran inéditos. A esta singular apelación a abrir una Revista de italianistas españoles acudieron Giorgio Bàrberi Squarotti, Giuseppe Bonaviri, Gina Lagorio, José Ledesma Criado, Maurizio Maggiani, Luigi Malerba, Giuseppe Pontiggia, Francesca Sanvitale y Emilio Tadini.

Con ese aval inicial, continuó RSEI su recorrido hasta el número 11, correspondiente a 2017, procurando que su periodicidad fuera anual, aunque dificultades de muy diverso tipo han impedido que fuera exactamente así. Sin embargo, creo, el balance en cuanto a la cantidad y calidad de los colaboradores y de los ensayos es lo suficientemente positivo, pues en RSEI han colaborado muchos investigadores, y se han publicado más de ciento cincuenta textos.

Una de las problemáticas que se abordaron en el momento inicial de su creación fue la de optar por números abiertos en cuanto a las temáticas, lo que garantizaba una afluencia mayor de textos y abría la posibilidad a más investigadores de participar. O el de elaborar números monográficos donde primaran la exhaustividad y especialización de las temáticas abordadas. Ambas disyuntivas eran válidas científicamente y podían apoyarse en la forma de hacer de revistas de prestigio de diferentes países y áreas de conocimientos, y, por ello, se optó por un sistema ecléctico, donde, primando la línea de temática abierta, no se cerrara a la elaboración de volúmenes monográficos.

Otra cuestión no planteada explícitamente, pero que sí está latente en lo referente a las temáticas, es la relación existente entre estudios de tipo lingüístico y de tipo literario. La praxis y el devenir del tiempo han ido dando primacía en cuanto a la cantidad a los estudios de crítica y análisis literario, aunque no faltan los análisis lingüísticos de tipo sincrónico y diacrónico o los referentes a la interrelación lengua-literatura. A ello se añade un número importante de artículos dedicados a los estudios contrastivos, especialmente a los de literatura ítalo-espańola, cada vez más documentados y cuidados por parte de los italianistas espańoles. Otros dedicados a la literatura italiana escrita por mujeres, género en el que las italianistas de España e Italia son pioneras y en que colaboran muy activamente.

Como he señalado, la variabilidad temática es muy amplia y bastan para ejemplificarla los títulos de los artículos de dos números. Así, en el volumen 3, de 2005, 
encontramos: Dino Buzzatti: tríptico antifacista; Representación grafemática de los sonidos palatales en el vulgar italiano durante los siglos XIV y XV; Juan Ramón Jiménez $y$ la literatura italiana; Homógrafos y homófonos en español y en italiano (formas verbales); C. Magris y su experiencia de frontera; Algunos aspectos de la proyección de la Commedia dell'Arte en España; Istantanea di un'Italia che cambia: i racconti di Luca Doninelli e Vincenzo Pardini; Planteamientos teóricos y metodológicos de la enseñanza del italiano; Giuseppe Ungaretti. Una poética della migrazione, etc.

Frente a alternancia de estudios de tipo lingüísticos y de crítica literaria, en el número 10 (2014) la mayoría de los artículos abordan argumentos literarios, incluidos los de género. Así, Due noviembre 1975. Cronaca di una morte annunciata; Caterina e e le altre: scrittrici mistiche italiane e Querelle des femmes; La traduzione filmica: un confronto preliminare tra due paesi "gemelli", l'Italia e la Spagna; A due voci: Pasolini legge a Rebora; L'eccezionalità di Giuseppina Turrisi Colonna nella Sicilia del XIX secolo; La puesta en escena del "diverso" pasoliniano. Ambigüedad, transgresión y resistencia en Porcile; Las relaciones entre la comida y la literatura: entre los fogones de la historia; L'occhio che guarda "altrove» di Mattia Pascal, etc.

Los dos números monográficos más relevantes, a mi entender, son el 14 (2007) dedicado a Giosuè Carducci, y el número 9 (2013) titulado En torno a Maquiavelo. En el primero colaboraron eminentes especialistas del Premio Nobel italiano, como Andrea Battistini, Arnaldo Bruni, Assumpta Camps Olivé, Renzo Cremante. Miquel Edo i Julià y Vicente González Martín.

En el dedicado a Maquiavelo se reunieron once artículos procedentes de especialistas de diversas áreas de conocimiento que abordaron la temática en torno a Maquiavelo desde las perspectivas literarias, filosóficas, históricas y jurídicas.

La estructura de cada uno de los números se completa con la publicación de diversas reseńas que tratan de describir y difundir algunas de las publicaciones relevantes contemporáneas al volumen en cuestión y de forma muy esporádica con alguna edición crítica no muy amplia de alguna obra italiana inédita o de muy difícil consulta, generalmente del Renacimiento.

En definitiva, RSEI. Revista de la Sociedad Española de Italianistas, con el número que está a punto de aparecer, completa dieciocho años de andadura con sus luces y sus sombras. Mantener una revista con continuidad es una tarea ardua no sólo por la dificultad de asegurar la financiación, sino también por todos los escollos que las reglamentaciones impuestas por la «indexación» imponen a las revistas científicas, que, más que favorecer la calidad, imponen la forma sobre la validez de los contenidos científicos y condicionan que las investigaciones en las áreas de Humanidades miren más a los índices que a la validez científica de sus contenidos. 